\title{
Targeting BCL2 Family in Human Myeloid Dendritic Cells: A Challenge to Cure Diseases with Chronic Inflammations Associated with Bone Loss
}

\author{
Selma Olsson Åkefeldt, ${ }^{1,2,3,4,5}$ Mohamad Bachar Ismail, ${ }^{2,3,4,5}$ Hélène Valentin,, ${ }^{2,3,4,5}$ \\ Maurizio Aricò, ${ }^{6}$ Jan-Inge Henter, ${ }^{1}$ and Christine Delprat ${ }^{2,3,4,5,7,8}$ \\ ${ }^{1}$ Childhood Cancer Research Unit, Department of Women's and Children's Health, Karolinska Institutet, \\ Karolinska University Hospital Solna, 17176 Stockholm, Sweden \\ ${ }^{2}$ CNRS, UMR5239, Laboratoire de Biologie Moléculaire de la Cellule, 69007 Lyon, France \\ ${ }^{3}$ Ecole Normale Supérieure de Lyon, 69007 Lyon, France \\ ${ }^{4}$ Université de Lyon, 69003 Lyon, France \\ ${ }^{5}$ Université de Lyon 1, 69622 Villeurbanne, France \\ ${ }^{6}$ Department of Pediatric Hematology Oncology, Azienda Ospedaliero-Universitaria, Meyer Children's Hospital, 50139 Florence, Italy \\ ${ }^{7}$ Institut Universitaire de France, 75005 Paris, France \\ ${ }^{8}$ CNRS 5239, Faculte De Medecine Lyon Sud, 165 Chemin du Grand Revoyet BP12, 69921 Oullins Cedex, France
}

Correspondence should be addressed to Christine Delprat; cdelprat@free.fr

Received 1 February 2013; Revised 8 April 2013; Accepted 22 April 2013

Academic Editor: Mohamad Mohty

Copyright (C) 2013 Selma Olsson Åkefeldt et al. This is an open access article distributed under the Creative Commons Attribution License, which permits unrestricted use, distribution, and reproduction in any medium, provided the original work is properly cited.

\begin{abstract}
Rheumatoid arthritis (RA) and Langerhans cell histiocytosis (LCH) are common and rare diseases, respectively. They associate myeloid cell recruitment and survival in inflammatory conditions with tissue destruction and bone resorption. Manipulating dendritic cell (DC), and, especially, regulating their half-life and fusion, is a challenge. Indeed, these myeloid cells display pathogenic roles in both diseases and may be an important source of precursors for differentiation of osteoclasts, the bone-resorbing multinucleated giant cells. We have recently documented that the proinflammatory cytokine IL-17A regulates long-term survival of DC by inducing BCL2A1 expression, in addition to the constitutive MCL1 expression. We summarize bibliography of the BCL2 family members and their therapeutic targeting, with a special emphasis on MCL1 and BCL2A1, discussing their potential impact on RA and LCH. Our recent knowledge in the survival pathway, which is activated to perform DC fusion in the presence of IL-17A, suggests that targeting MCL1 and BCL2A1 in infiltrating DC may affect the clinical outcomes in RA and LCH. The development of new therapies, interfering with MCL1 and BCL2A1 expression, to target long-term surviving inflammatory DC should be translated into preclinical studies with the aim to increase the well-being of patients with RA and LCH.
\end{abstract}

\section{Introduction}

Myeloid dendritic cells (DCs) can be derived from monocytes in the presence of GM-CSF and IL-4, both in vitro and in vivo [1]. Therefore, DC and monocytes are closely related. They share (Figure 1) the ability to phagocytose extracellular bacteria, to synthesize the apoptotic factor TRAIL in response to interferons (IFN) in the context of viral infections [2,3], and to present antigens to $\mathrm{T}$ cells. They also undergo cell fusion in the presence of M-CSF and RANKL, thus forming osteoclasts (OCs), the bone-resorbing multinucleated giant cells (MGCs) $[4,5]$. By contrast, two functional properties discriminate DC from monocytes. First, DCs initiate adaptive immune responses versus tolerance, as demonstrated in mouse models of DC short-term ablation, in vivo [6]. Second, DCs undergo cell fusion in the presence of the pro-inflammatory cytokine 


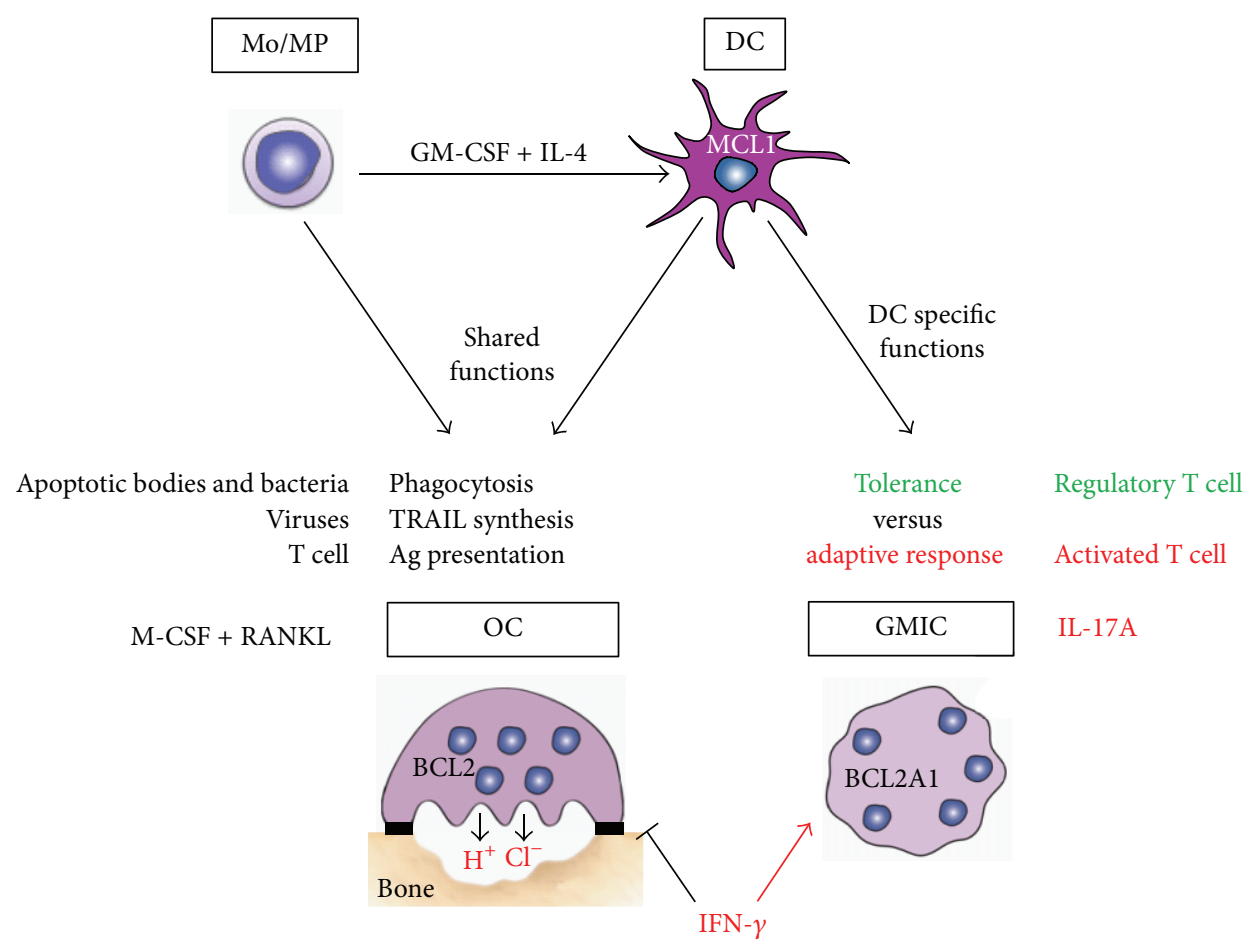

FIGURE 1: Dendritic cell functions compared to monocytes. Monocyte-derived DCs share four functions with monocytes: phagocytosis, TRAIL synthesis, Ag presentation, and differentiation into OC in the presence of M-CSF and RANKL. Conversely, initiation of tolerance, adaptive response, and IL-17A-dependent differentiation of GMIC are DC-specific functions. IFN- $\gamma$ differentially regulates MGC formation by inhibiting OC and stimulating GMIC formation.

IL-17A, a mechanism highly potentiated by IFN- $\gamma[7,8]$. To discriminate OC from the IL-17A-dependent MGC, these latter will be called giant myeloid inflammatory cells (GMICs) in this review. Exacerbation of these fusion pathways may be involved in two diseases of unknown etiology: rheumatoid arthritis (RA) and a rare disease called Langerhans cell histiocytosis (LCH). In both diseases, bone loss is observed, and the three cytokines M-CSF, RANKL, and IL-17A have been detected [7, 9-11]. While untreated immature DCs have a short two-day lifespan, both OC and GMIC survive more than two weeks, thus demonstrating that survival pathways are activated along the DC fusion process, in vitro. In 2008, it was shown that B-cell lymphoma 2 (BCL2) is critical for OC survival as demonstrated by the increased bone mass of $\mathrm{BCL}^{-/-}$mice [12]. We have recently documented that an unexpected member of the BCL2 family, BCL2A1, is involved in the survival of GMIC [13]. In the light of this last finding, we reviewed the available knowledge to investigate whether targeting members of the BCL2 family in DC may open novel treatment opportunities in chronic inflammatory diseases associated with bone loss. We first focus on the two BCL2 members expressed by DC, MCL1, and BCL2A1. Then, we review the therapeutic compounds able to target MCL1 or BCL2A1. Finally, we discuss challenges and opportunities to target MCL1 and BCL2A1 in RA and LCH, in the aim to block formation of OC and GMIC from DC.

\section{Bcl2 Family and the Focus on MCL1 and BCL2A1 Expressed by Myeloid Dendritic Cells}

Apoptosis is initiated by extrinsic and intrinsic pathways, depending on the stimulus, as death receptor ligation on the cell surface (Fas, TNFRSF1, TNFRSF10, etc.) and intracellular stress (UV, cytokine withdrawal, cytotoxic drugs, etc.), respectively [14]. Ligation of death receptors causes formation of a death-inducing signaling complex (DISC) that triggers caspases and then apoptosis, independently of mitochondria. Such mechanism can be inhibited by CFLAR (or viral homologs), previously named FLICE-inhibitory proteins (FLIP). Interestingly, myeloid DCs expressing Fas on their membrane were not sensitive to Fas-mediated apoptosis unless sensitized by cycloheximide [15]. This resistance is attributed to the expression of CFLAR by myeloid DC. By contrast, immature (but not mature) human myeloid DCs are very sensitive to UVB irradiation [16], a process involving intracellular oxidative stress and caspase activation through the intrinsic pathway of apoptosis.

The mitochondria-dependent intrinsic pathway involves the BCL2 members, whose main functions include embryogenesis control, tissue homeostasis, leukocyte development, and defense against pathogens. The BCL2 family displays three groups of proteins, sharing sequence homology in 
Multidomain prosurvival proteins

$\mathrm{BCL} 2 \mathrm{~L} 1$
$\mathrm{BCL} 2 \mathrm{~L} 2$
$\mathrm{MCL} 1$
$\mathrm{BCL} 2 \mathrm{~A} 1$

Multidomain proapoptotic proteins
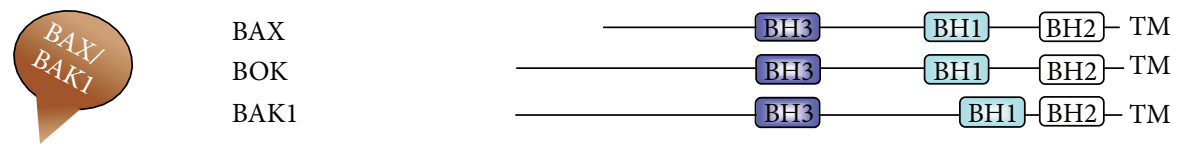

BH3-only proapoptotic proteins

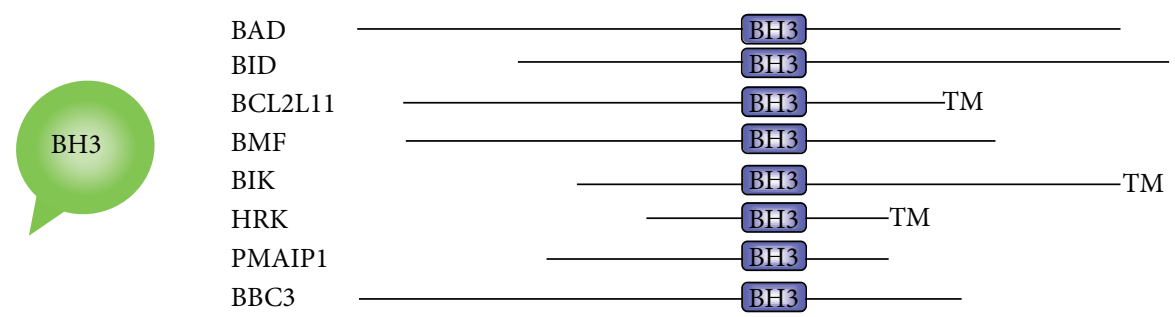

FIGURE 2: Classification of the BCL2 family into three subfamilies of BCL2-related proteins. The four BCL2 homology (BH) domains are the most highly conserved among BCL2 family. The prosurvival proteins contain four $\alpha$-helix BH domains (BH1-4). BH1-3 domains of prosurvival proteins form a hydrophobic cleft that binds proapoptotic proteins through their hydrophobic $\mathrm{BH} 3$ domains. The multidomain proapoptotic proteins have BH1-3 domains, while the proapoptotic BH3-only proteins share only the BH3 domain with the other BCL2-related proteins. Most members have a carboxy-terminal hydrophobic transmembrane (TM) domain, with the exceptions of many of the BH3-only proteins and probably BCL2A1.

their BCL2 homology (BH) domains (Figure 2, Table 1). They include the prosurvival proteins (such as BCL2, MCL1, and BCL2A1) and the proapoptotic proteins, comprising the multidomain proteins (such as BAX and BAK1) and the BH3only proteins (including BAD, BID, and BIM) [17]. How these three groups integrate cell signaling into the decision to live or die is not completely understood and the mechanism remains controversial [18]. A set of interactions between BCL2 members ultimately controls the release of cytochrome $c$ from mitochondria, the caspase activation, and then apoptosis. In living normal cells, proapoptotic proteins are sequestered by prosurvival members, thus inhibiting the release of cytochrome c from mitochondria (Figure 3(a)). However, there are some reports indicating that the mitochondria are not essential for initiation of cell death induced from intrinsic pathway and that apoptosis can also occur in the absence of caspase activation [19]. After an intracellular apoptotic stimulus, the $\mathrm{BH} 3$-only proteins activate the multidomain proapoptotic proteins, thereby triggering cytochrome c release and apoptosis (Figure 3(b)). Impaired apoptosis associated with an enhanced expression of prosurvival BCL2 proteins is a hallmark of human cancers (Figure 3(c)) and is frequently associated with resistance to therapy $[18,20,21]$. In addition, upregulation of prosurvival BCL2 proteins has also been observed in chronic inflammatory disorders.
Compared to lymphocytes, relatively little knowledge is available on the regulation of myeloid cell survival by the BCL2 family members. Among the prosurvival proteins, both MCL1 and BCL2A1 appear to have physiologically important roles in regulating myeloid cell survival. MCL1 is expressed at steady state in neutrophils, monocytes, and DC, but not in macrophages, unless they are activated [21, 22]. MCL1 provides short-term enhancement of myeloid cell survival during the critical transition differentiation process [22]. In normal or tumoral myeloid cells, the cytokines GMCSF, IFN- $\alpha$, IL-3, IL-5, IL-6, IL-15, or IL-22 upregulate MCL1 expression [22]. Upon exposure to pro-inflammatory cytokines, MCL1 is upregulated in granulocytes, monocytes, and macrophages and associated with BCL2A1 induction [19]. During chronic inflammatory diseases, apoptosis of neutrophils is significantly delayed due to upregulation of MCL1 [23]. Interestingly, BCL2A1 is not expressed in myeloid cells at steady state; yet, inflammatory stimuli including bacterial endotoxin like lipopolysaccharide, G-CSF, GMCSF, IL- $1 \beta$, TNF- $\alpha$, IFN- $\gamma$, IL-8, and IL-17A induce it, thus extending the survival of neutrophils, granulocytes, mast cells, macrophages, and, as we recently documented, DC $[13,19,24-26]$. BCL2A1, an NF- $\kappa \mathrm{B}$ target gene expressed in activated myeloid cells, supports key function in inflammation. In chronic inflammatory disorders, regulation of MCL1 
TABLE 1: Approved Hugo gene nomenclature of the BCL2 family.

\begin{tabular}{|c|c|c|c|c|}
\hline Approved symbol & Approved name & Activity & Location & Synonym \\
\hline BCL2 & B-cell CLL/lymphoma 2 & Prosurvival & $18 \mathrm{q} 21.3$ & Bcl-2, PPP1R50 \\
\hline BCL2L1 & BCL2-like 1 & Prosurvival & $20 \mathrm{q} 11.21$ & $\begin{array}{c}\text { Bcl-X, bcl-xL, bcl-xS, } \\
\text { BCL2L, BCLX, PPP1R52 }\end{array}$ \\
\hline BCL2L2 & BCL2-like 2 & Prosurvival & $14 \mathrm{q} 11.2-\mathrm{q} 12$ & BCL-W, KIAA0271, PPP1R51 \\
\hline MCL1 & $\begin{array}{l}\text { Myeloid cell leukemia sequence } 1 \\
\text { (BCL2-related) }\end{array}$ & Prosurvival & $1 \mathrm{q} 21$ & BCL2L3, Mcl-1 \\
\hline BCL2A1 & BCL2-related protein A1 & Prosurvival & $15 \mathrm{q} 24.3$ & $\begin{array}{l}\text { ACC-1, ACC-2, } \\
\text { BCL2L5, BFL1, GRS }\end{array}$ \\
\hline BAX & BCL2-associated X protein & $\begin{array}{l}\text { Proapoptotic } \\
\text { multidomain }\end{array}$ & 19q13.3-q13.4 & BCL2L4 \\
\hline BOK & BCL2-related ovarian killer & $\begin{array}{l}\text { Proapoptotic } \\
\text { multidomain }\end{array}$ & $2 \mathrm{q} 37.3$ & BCL2L9, BOKL, MGC4631 \\
\hline BAK1 & BCL2-antagonist/killer 1 & $\begin{array}{l}\text { Proapoptotic } \\
\text { multidomain }\end{array}$ & $6 \mathrm{p} 21.31$ & BAK, BCL2L7 \\
\hline $\mathrm{BAD}$ & BCL2-associated agonist of cell death & $\begin{array}{l}\text { Proapoptotic } \\
\text { BH3-only }\end{array}$ & $11 \mathrm{q} 13.1$ & BBC2, BCL2L8 \\
\hline BID & $\mathrm{BH} 3$ interacting domain death agonist & $\begin{array}{l}\text { Proapoptotic } \\
\text { BH3-only }\end{array}$ & $22 \mathrm{q} 11.2$ & - \\
\hline BCL2L11 & $\begin{array}{c}\text { BCL2-like } 11 \\
\text { (apoptosis facilitator) }\end{array}$ & $\begin{array}{l}\text { Proapoptotic } \\
\text { BH3-only }\end{array}$ & $2 \mathrm{q} 13$ & $\begin{array}{l}\text { BIM, BimEL, BimL, } \\
\text { BimS, BOD }\end{array}$ \\
\hline BMF & BCL2 modifying factor & $\begin{array}{l}\text { Proapoptotic } \\
\text { BH3-only }\end{array}$ & $15 q 14$ & FLJ00065 \\
\hline BIK & $\begin{array}{l}\text { BCL2-interacting killer } \\
\text { (apoptosis-inducing) }\end{array}$ & $\begin{array}{l}\text { Proapoptotic } \\
\text { BH3-only }\end{array}$ & $22 \mathrm{q} 13.31$ & NBK \\
\hline HRK & Harakiri, BCL2 interacting protein & $\begin{array}{l}\text { Proapoptotic } \\
\text { BH3-only }\end{array}$ & $12 \mathrm{q} 24.2$ & DP5 \\
\hline PMAIP1 & $\begin{array}{l}\text { Phorbol-12-myristate-13-acetate-induced } \\
\text { protein } 1\end{array}$ & $\begin{array}{l}\text { Proapoptotic } \\
\text { BH3-only }\end{array}$ & $18 q 21.32$ & APR, NOXA \\
\hline $\mathrm{BBC} 3$ & BCL2 binding component 3 & $\begin{array}{l}\text { Proapoptotic } \\
\text { BH3-only }\end{array}$ & $19 \mathrm{q} 13.3-\mathrm{q} 13.4$ & JFY1, PUMA \\
\hline
\end{tabular}

and BCL2A1 gene expressions results in recruitment and stabilization of myeloid cells of the immune system $[27,28]$. We propose that, in healthy DC, while MCL1 expression provides short-term (two days) survival, additional BCL2A1 expression switches the DC phenotype and allow longterm survival. In this context, BCL2A1 induction operates downstream of NF- $\kappa$ B activation in IL-17A-stimulated DC [13] and may be very important in sustaining chronic T-cell activation in IL-17A-related diseases. This new concept places IL-17A-stimulated $\mathrm{MCL1}^{+} \mathrm{BCL}^{-\mathrm{Al}^{+}} \mathrm{DC}$ in the sunlight and makes MCL1 and BCL2A1 novel attractive therapeutic targets in chronic inflammatory diseases.

\section{Targeting MCL1 and BCL2A1 by Chemotherapeutic Compounds}

To overcome BCL2-family-mediated resistance to chemotherapy, different strategies have been tried, including their targeting by antisense oligonucleotides peptide inhibitors and small molecules inhibitors (SMIs) [29, 30]. Most widely used so far is the SMI ABT-737 (and its orally active follow-up ABT-263) which mimics the $\mathrm{BH} 3$-only proteins and binds with high-affinity BCL2, BCL2L1, and BCL2L2, inducing apoptosis in a BAX-and BAK-dependent way [31]. However, it binds only weakly to MCL1 and BCL2A1, and resistance to ABT-737 has been associated with high expression of MCL1 and BCL2A1 [32, 33].

Expression of both MCL1 and BCL2A1 has, in several hematological malignancies, been associated with chemoresistance or poor prognosis $[34,35]$; thus, new drugs targeting these proteins must be developed. Some of the SMIs under development, including Obatoclax and Sabutoclax, have been shown to better target MCL1 or MCL1 and BCL2A1, respectively [36, 37]. Sorafenib, developed as a BRAF inhibitor, reduces MCL1 translation leading to increased apoptosis in leukemia cells [38] while Flavopiridol, a cyclin-dependent kinase inhibitor, suppresses MCL1 and has been used to treat patients with high-risk chronic lymphocytic leukemia (CLL) $[39,40]$.

We recently showed that monocyte-derived DCs, treated with IL-17A and IFN- $\gamma$ that mimic chronic inflammation conditions, develop resistance to apoptosis. This resistance is associated with a robust coexpression of MCL1 and BCL2A1 and is dependent on IL-17A that induces BCL2A1 in MCL1 ${ }^{+}$ DC [13]. IL-17A- and IFN- $\gamma$-treated DCs were resistant to a variety of chemotherapeutic drugs. However, they were highly sensitive to the antimicrotubule drugs vinblastine and, to a lesser extent, vincristine and cytarabine. We showed 


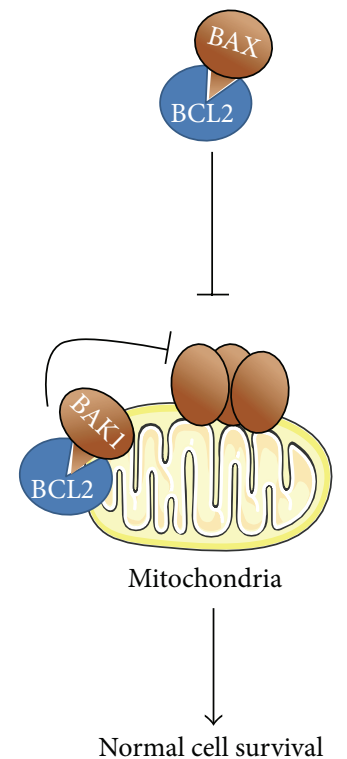

(a) At steady state or response to activation signals: BCR, TCR, CD40, proinflammatory cytokines, and so on

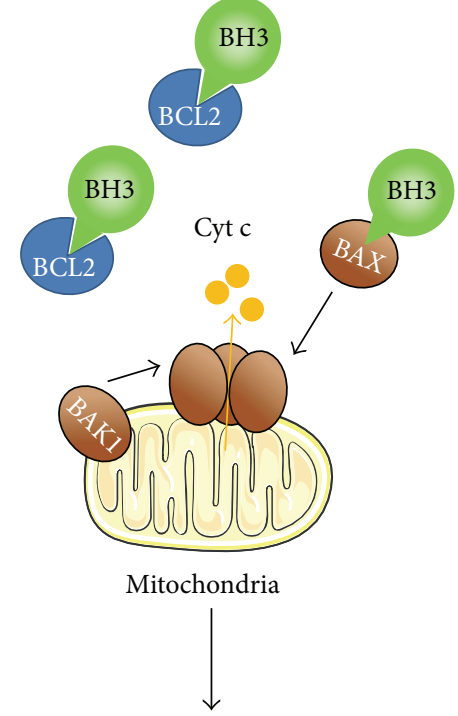

Apoptosis of damaged cells

(b) Response to intracellular damage signals: growth factor deprivation, stress, UV, viruses, and so on

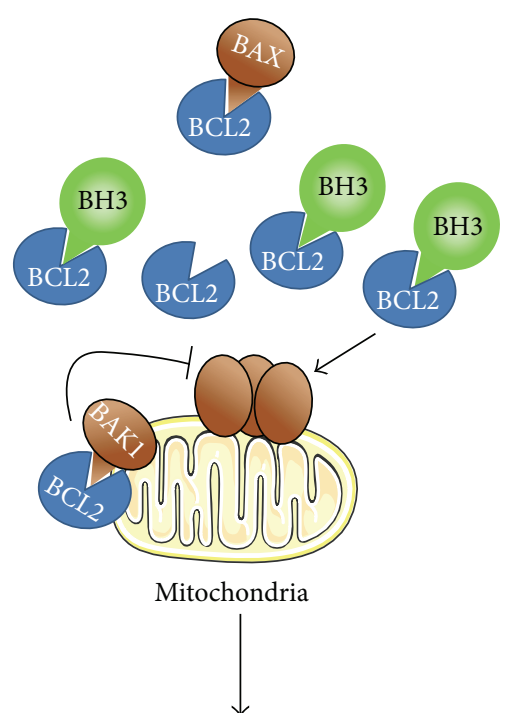

Abnormal cell survival

(c) In cancers or chronic inflammatory disorders: oncogenes, viruses, proinflammatory cytokines, and so on

FIgURE 3: Model of survival control by the BCL2 family in physiological and inflammatory conditions. (a) In a physiological context or following an immune response, constitutive or inducible prosurvival proteins (here BCL2) bind multidomain proapoptotic proteins (BAX, BAK) that become unable to oligomerize, thereby resulting in normal cell survival at steady or activated state. (b) In response to intracellular damage, activator BH3-only proteins are induced or activated. They inhibit the prosurvival proteins and activate the effector multidomain proapoptotic proteins, which in turn are homooligomerize, triggering cytochrome c release (Cyt c) and apoptosis. Potentially abnormal cells are then eliminated. (c) In a pathological context, such as cancers and chronic inflammatory diseases, prosurvival proteins are upregulated, inhibiting the multidomain and $\mathrm{BH} 3$-only proapoptotic proteins. As a result, the membrane of mitochondria remains intact and abnormal cells survive.

that exposure to vinblastine or cytarabine decreased MCL1 expression. Antimicrotubuli agents are widely used in various cancers, including hematological malignancies [41]. They induce mitotic arrest and trigger apoptosis through mechanisms which are not fully clear. However, Wertz et al. recently showed that vincristine-induced apoptosis is mediated by the molecular partnership between the ubiquitin-ligase FBW7 and MCL1, once it has been phosphorylated, downstream of vincristine treatment [42]. Ubiquitination of phospho-MCL1 by FBW7 led to the destruction of MCL1 by the proteasome. Our recent studies documented MCL1 degradation by vinblastine. We also confirmed that adding vinblastine to GMIC led to disorganization of the microtubule network and cell death.

IL-17A- and IFN- $\gamma$-treated DCs also underwent apoptosis upon addition of antibodies neutralizing IL-17A, which selectively reduced BCL2A1 expression. Our interpretation is that the long-term DC survival is dependent on both MCL1 and BCL2A1 expressions. In the future, it would be interesting to evaluate the targeting of both MCL1 and BCL2A1 in chronic IL-17A-related inflammatory diseases, using either Sabutoclax or the combination of toxic compounds targeting MCL1 (such as vinblastin, vincristine, cytarabine, or Obatoclax) with antibodies neutralizing IL-17A, the pro-inflammatory cytokine that induces BCL2A1 in human DC.

\section{Role of Dendritic Cells and Regulatory $T$ Cells in Rheumatoid Arthritis}

RA is a chronic inflammatory disease of the synovium, a delicate membrane that lines the nonweight-bearing surfaces of the joint. In the absence of disease, synoviocytes produce factors that provide nutrition and lubrication for the surrounding cartilage tissue; few cellular infiltrates are seen in the synovium. In RA, the synovium is infiltrated by chronic inflammatory cells, such as macrophages, DC, neutrophils, T cells, and B cells. The resident fibroblasts adopt a quasi-malignant phenotype with upregulation of oncogenes, inhibition of apoptosis, and secretion of cytokines, chemokines, and enzymes that reinforce the inflammation and catalyse joint destruction. The resulting pannus acquires the ability to invade and destroy adjacent articular cartilage. Activation of OC in periarticular bone leads to resorption and erosion, a radiologically detectable hallmark of the disease. Similar processes affect the synovium that lines the tendon sheaths, resulting in tendon weakness and rupture, which are responsible for the characteristic deformities of RA. This is a potentially devastating disease that affects the whole individual, reducing the social contribution, destroying the quality of life, and ultimately shortening the patient's lifespan. Pro-inflammatory cytokines are amongst the most 


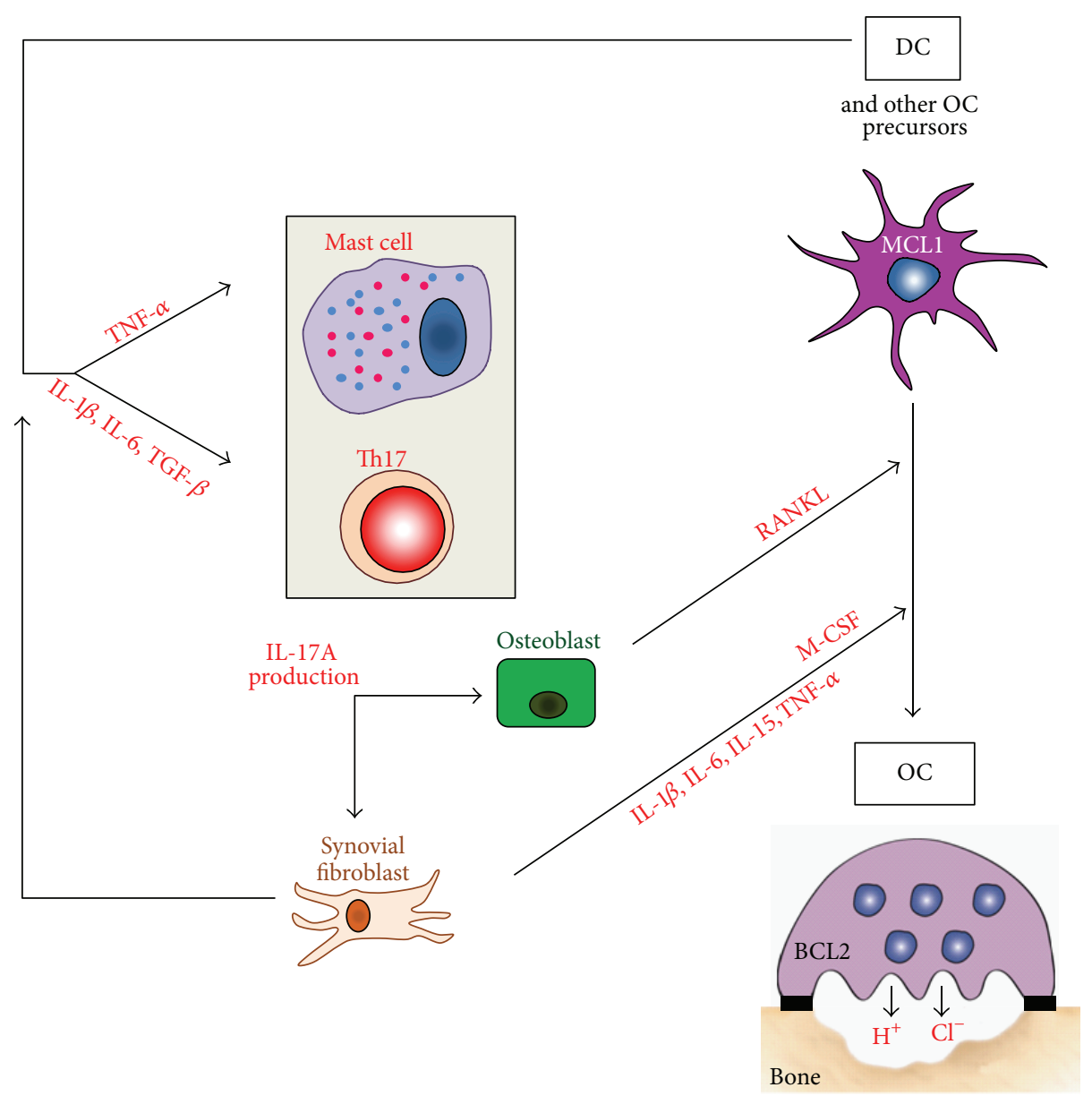

FIGURE 4: Pro-inflammatory cytokines drive bone resorption in rheumatoid arthritis. Cytokines are amongst the most important mechanisms driving bone resorption associated to inflammation mediated by M-CSF, RANKL, TNF- $\alpha$, IL-1- $\beta$, IL-6, and finally IL-17A. In RA, IL$17 \mathrm{~A}$ is mainly produced by Th17 and mastocytes, further amplifying inflammation by enhancing pro-inflammatory cytokine production of synovial fibroblast. IL-17A also increases bone resorption by inducing RANKL production by osteoblasts and M-CSF production by synovial fibroblasts; M-CSF and RANKL are the two cytokines required to differentiate OC from different cell sources: DC, monocytes, macrophages, or bone-marrow progenitors.

important mechanisms driving this process. In particular, M-CSF, RANKL, TNF- $\alpha$, IL-1, and IL-17A play dominant roles in the pathogenesis of arthritis-associated bone loss (Figure 4). A common first line of treatment is methotrexate monotherapy, while nonresponders are treated with agents neutralizing TNF- $\alpha$ activity. Recently, in a phase I clinical study, biotherapy involving neutralization of IL-17A reduced signs and symptoms of RA with no strong adverse effects [43].

DCs are key players in RA. Rheumatoid synovium is characterized by accumulation of immature and mature DC subsets perivascularly, in close association with $\mathrm{T}$ cells and B-cell follicles [44-46]. Synovial fluid contains significant numbers of myeloid DC compared to blood, suggesting a role for these antigen presenting cells in disease perpetuation [47, 48]. DC may contribute to ongoing inflammation through presentation of autoantigens, as suggested by animal models of autoimmune arthritis [49] or secretion of crucial pro-inflammatory mediators or differentiation into OC [4]. Whether regulatory $\mathrm{T}$-cell $\left(\mathrm{T}_{\mathrm{REG}}\right)$ defects are present in patients with RA is not clear. The number of $\mathrm{CD} 4^{+} \mathrm{CD} 25^{\text {high }} \mathrm{T}_{\mathrm{REG}}$ in the peripheral blood of patients with RA was found to be higher than in healthy individuals in one study, but not in others [50]. DCs show evidence of activation in vivo: upregulation of $\mathrm{MHC}$, costimulatory molecules, and expression of NF- $\kappa \mathrm{B}$, RANKL, and RANK [51]. The killing of activated DC and the investigation of tolerance induction by shaping DC plasticity towards tolerogenic $\mathrm{DC}$ may possibly give rise to a withdrawal of therapy.

\section{Targeting MCL1 and BCL2A1 in Rheumatoid Arthritis}

MCL1 is critical for the survival of macrophages in the joints of patients with RA, thus representing a potential therapeutic target in this disease [52]. In a mouse study, BIM-BH3 mimetic therapy reduced arthritis through the activation of myeloid cell apoptosis, thus demonstrating that $\mathrm{BH} 3$ mimetic therapy may have a significant potential for the treatment of RA [53]. More recently, Oliveira et al. evaluated gene 


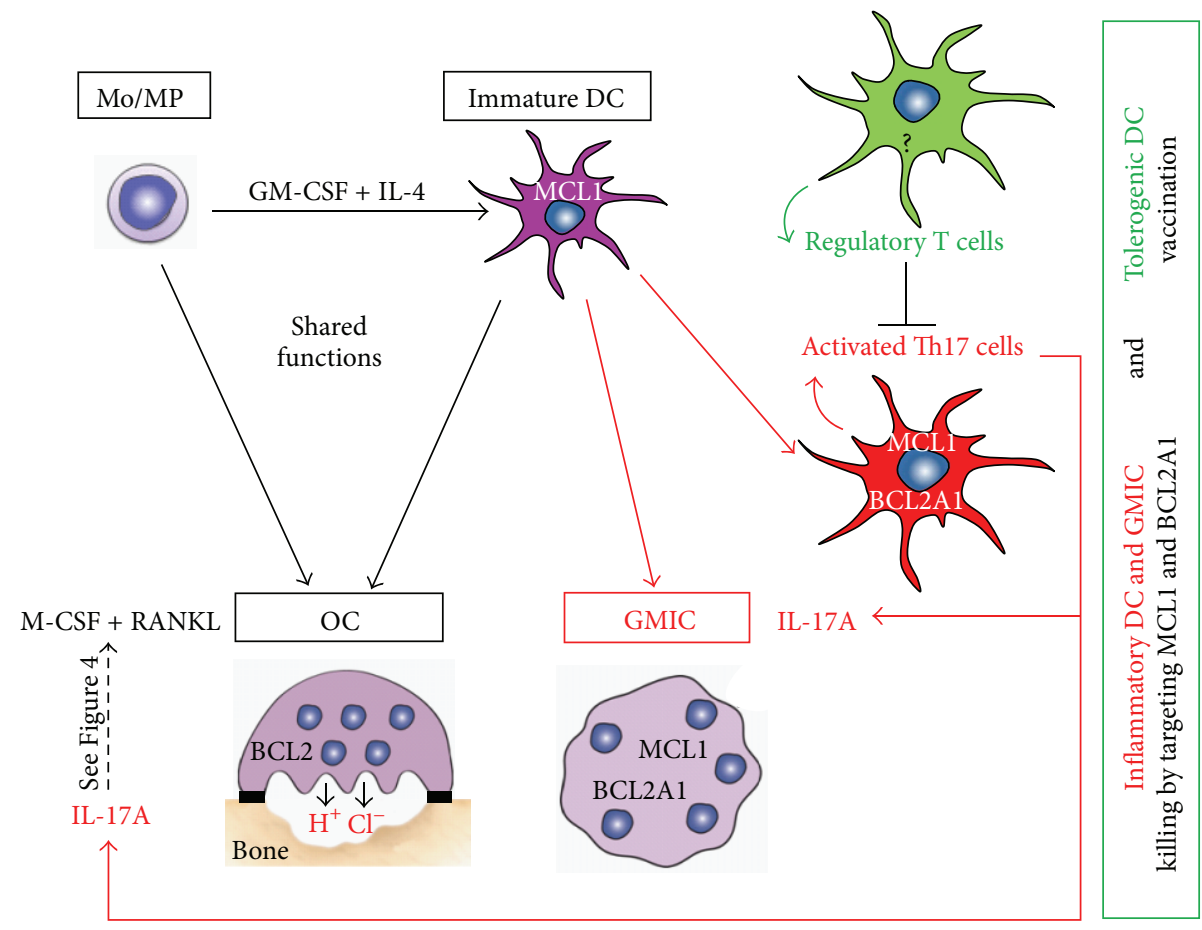

Figure 5: Model for the therapeutical management of diseases associated with IL-17A-dependent chronic inflammation with bone loss. In the context of IL-17A-driven inflammation, IL-17A amplifies OC formation and consequently bone resorption (see details in Figure 4). In addition, IL-17A induces BCL2A1 expression in $\mathrm{MCL1}^{+}$monocyte-derived DC, DC clustering, and fusion, leading to a mixed culture, containing both mononuclear and multinuclear (GMIC) inflammatory DC. These inflammatory DC and GMIC express MCL1 and BCL2A1 contrary to OC whose survival is under the control of BCL2. Tolerogenic DCs activate regulatory T cells able to control activated Th17 cells. The question mark indicates that the status of BCL2 family in tolerogenic DC is unknown and should be studied to validate this model. In order to cure diseases with IL-17A-dependent chronic inflammation associated with bone loss, we suggest killing inflammatory DC and GMIC by targeting both MCL1 and BCL2A1. In parallel performing therapeutic autologous vaccination with tolerogenic DC may help breaking IL-17A-dependent chronic inflammation to restore normal bone physiology.

expression profiles of (i) RA patient responders and nonresponders to methotrexate and, in the case of nonresponders, (ii) the responders and nonresponders to methotrexate combined with anti-TNF- $\alpha$ biotherapy [54]. They identified nine genes in methotrexate nonresponders and three genes in methotrexate plus anti-TNF- $\alpha$ nonresponders. Two genes were common in both lists: CCL4 and BCL2A1. This is a strong argument to further evaluate the role of BCL2A1 in RA and, in particular, a potentially overlooked role of long-term surviving IL-17A-stimulated $\mathrm{MCL1}^{+} \mathrm{BCL}^{\mathrm{Al}} 1^{+}$activated DCs. Segura et al. have just characterized that inflammatory DCs, found in human inflammatory fluids, represent a distinct human DC subset, sharing gene signatures with in vitro monocyte-derived DC and involved in the induction and maintenance of Th17 cell responses [55]. If the survival pathway of these inflammatory DC is different from that of tolerogenic DC (Figure 5), it would be possible, on the one hand, to vaccinate with autologous DC exhibiting potent tolerogenic functions and, on the other hand, to induce apoptosis of inflammatory DC, in order to reinstate immune tolerance [56] and to abrogate IL-17A-dependent DC-driven inflammation.

\section{Role of Dendritic Cells and Regulatory $T$ Cells in Langerhans Cell Histiocytosis}

LCH is a rare disease which belongs to the histiocytic disorders characterized by tissue damage induced by infiltrating cells (histiocytes), derived from the monocytic lineage [57]. LCH occurs predominantly in children but can occur at any age. Clinical manifestations can vary from a single selfresolving lesion to a severe life-threatening systemic form. Multiple organs may be affected by this disease including bone ( $80 \%$ of the patients), skin, lymph nodes, endocrine glands, and the central nervous system. LCH lesions are heterogeneous and form aggressive granulomas containing $\mathrm{CDla}^{+} \mathrm{CD} \mathrm{C7}^{+/-}$cells (presumed to be pathogenic $\mathrm{LCH}$ cells) admixed with macrophages, $\mathrm{T}$ cells, eosinophils, and MGC [58]. Killing the lesional tissue-aggressive LCH cells is difficult but may be achieved in most patients by chemotherapy regimens containing the combination of prednisone and vinblastine or, in salvage settings, cladribine and cytarabine.

The exact origin of pathogenic LCH cells is unclear. Based on many common features, it was proposed that they arise from epidermal CD207 ${ }^{+}$Langerhans cells. However, in 2008, 
we proposed that pathogenic DC may derive from monocytes rather than belonging to the Langerhans cell lineage [7]. This is, in keeping with data from a recent gene expression profile study of human cells isolated from LCH granulomas, also suggesting that LCH lesions originate from accumulation of immature myeloid DC rather than epidermal Langerhans cells [59]. Finally, LCH DCs exhibit a unique transcription profile that separates them from all previously known DCs based on their expression of both Notch ligand and its receptor [60].

The etiology of LCH remains controversial between an inflammatory disorder, a neoplasm, or even both since induction of long-term DC survival by inflammation may license accumulation of mutations; this might provide to LCH DC a more apoptotic-resistant behavior. Senechal et al. found that less than $2 \%$ of cells were proliferating within lesions and propose that pathogenic DC accumulation is mainly the consequence of increased survival rather than proliferation [61]. This was associated with a local and systemic expansion of CD2 $5^{\text {high }}$ FoxP3 $3^{\text {high }} \mathrm{T}_{\mathrm{REG}}$ possibly impairing the resolution of LCH granulomas [61]. Altogether, these data suggest that immunological mechanisms play the major role in the development of LCH. Furthermore, evidence of concordance for $\mathrm{LCH}$ in monozygous twins supports the concept of a genetic predisposition to develop $\mathrm{LCH}$, possibly affecting the immune system regulation [62]. However, Badalian-Very and colleagues found that 57\% (35 of 61) of examined $\mathrm{LCH}$ specimens display the oncogenic BRAF V600E mutation [63]. These findings were also confirmed by additional independent studies $[64,65]$. BRAF is a pivotal protein kinase of the RAS-RAF-MAPK signaling pathway which regulates cell survival and proliferation. In pathological LCH cells, constitutive activity of the mutant BRAF V600E protein may lead to a deregulated signaling through this pathway, thereby resulting in increased cell survival [66].

\section{Targeting MCL1 and BCL2A1 in Langerhans Cell Histiocytosis}

In LCH lesions, apoptotic pathways have been shown to be active alongside prosurvival pathways [67-69], and the expansion or healing of a granuloma is likely the sum of these apparently conflicting activities. Concerning the BCL2 family members, BCL2 expression was documented in $\mathrm{LCH}$ DC in two separate studies using immunohistochemistry and in situ hybridization $[68,69]$. However, BCL2 was not found to be elevated in $\mathrm{CD}_{20} 7^{+}$cells from LCH lesions analyzed by transcriptome analysis by Allen et al. [59], who instead showed upregulation of BCL2L1 and BAX. Similar data on BCL2L1 had been previously described in pulmonary LCH [70]. Whether upregulation of survival molecules in $\mathrm{LCH}$ is due to exogenous stimuli, such as cytokines, or intrinsic mutations such as BRAF V600E, in the RAS-RAF-MAPK signaling cascade [63] in a majority of samples from $\mathrm{LCH}$ biopsies, is still not clarified. So far, no other cancerogenic mutations have been found in LCH and the BRAF V600E mutation by itself is not sufficient for tumor development [71]. Southern blot analysis performed by the Savell team showed no evidence for gene rearrangement of the BCL2 gene [68]. An abundant number of cytokines have been described in LCH lesions, many with the potential to affect cell survival $[72,73]$. Considering the presence also of IL-17A in $\mathrm{LCH}$ and the therapeutic efficacy of vinblastine, targeting MCL1, it would be interesting to study the role of MCL1 and BCL2A1 in $\mathrm{LCH}$ and to correlate their expression to disease progress and drug resistance. Depending on these future studies, targeting MCL1 and BCL2A1 in LCH may be of importance, at least to prevent the intense bone resorption occurring in $80 \%$ of the patients with LCH.

\section{Exploiting DC Surface Molecules to Specifically Target BCL2A1-Expressing DC}

There are a variety of in vivo DC-targeting strategies used in different contexts including autoimmune disease therapies [74], vaccine-induced immunity [75], and cancer therapy [76]. Specific targeting of long-term survival BCL2A1 ${ }^{+}$DCs may form a promising therapeutic avenue in inflammatory conditions. Two different strategies can be suggested: inhibition of the intracytoplasmic activity of BCL2A1 or prevention of IL-17A signal transduction in DCs. In the former, a BCL2A1 inhibitory peptide (that should be developed) may be delivered directly to DCs by using a fusion protein built with this peptide and GM-CSF, whose receptor is expressed by $\mathrm{BCL}_{2} \mathrm{Al}^{+}$DCs. More specifically, it can be loaded into biodegradable nanoparticles attached to monoclonal antibodies that recognize specific DC surface receptor(s). Since human inflammatory DCs appear most likely to be derived from monocytes in vivo [55], a potential target surface receptor is CD209/DC-SIGN, expressed by these cells in tissues and absent on the surface of other DC subpopulations. Specific inhibition of IL-17A signal transduction in DCs may be achieved through an approach which combines antiDC-SIGN and anti-IL-17A antibodies. This may result in the neutralization of IL-17A and the subsequently induced BCL2A1 expression in DCs.

\section{Conclusion}

DCs are critical regulators of immune responses not only at initiation, but also, as recently demonstrated, for the maintenance of chronic inflammation, especially the IL-17A-driven chronic inflammation [55]. We demonstrated that IL-17A activates long-term survival pathway by inducing BCL2A1 in $\mathrm{DC}$, thus providing a molecular basis for DC maintenance in IL-17A-mediated chronic inflammation. Cytokines and BCL2-related survival pathway may interplay to determine not only myeloid cell accumulation and inflammatory DC maintenance, but also their fusion and final differentiation into either GMIC or OC, the bone-resorbing giant cells (Figure 5). This may affect the clinical course and final longterm outcomes of patients. However, fundamental research is required to solve the question mark: a better understanding of the disease-related alterations in BCL2-related survival pathways and functions of DC might offer the opportunity 
to design and fine-tune approaches aimed at killing inflammatory DC, while therapeutic vaccination may reintroduce tolerogenic DC. Since chemotherapy remains, at present, the standard of care for $\mathrm{LCH}$, introduction of immunemodulation is highly warranted. Currently available data suggest that manipulation of the BCL2 family (with the decrease of both MCL1 and BCL2A1) in DC, associated with a therapeutic vaccination with autologous tolerogenic DC, might represent a suitable treatment in rheumatoid arthritis and Langerhans cell histiocytosis, possibly leading to a cure.

\section{Abbreviations}

BCL2: B-cell lymphoma 2

BCL2A1: BCL2-related protein A1

DC: $\quad$ Dendritic cell

GMIC: Giant myeloid inflammatory cells

IFN: Interferon

LCH: Langerhans cell histiocytosis

MCL1: Myeloid cell leukemia sequence 1

MGC: Multinucleated giant cells

OC: Osteoclast

RA: Rheumatoid arthritis

SMI: $\quad$ Small molecules inhibitors

$\mathrm{T}_{\mathrm{REG}}$ : Regulatory $\mathrm{T}$ cell.

\section{Conflict of Interests}

The authors declare no conflict of interests.

\section{Acknowledgments}

This work was supported by grants from (F) CNRS, INSERM, Université de Lyon, Institut Universitaire de France, Fondation Innovations en Infectiologie, Fondation de France 2008002100, Agence Nationale de la Recherche 08-MIEN001-02; (USA) Histiocytosis Association of America 2008; (I) Ministero Sanità, Progetto di Ricerca Finalizzata 2008: "Getting deeper in histiocytosis," Regione Toscana, Progetto di Ricerca Malattie Rare 2008, Associazione Italiana Ricerca Istiocitosi (AIRI); (S) the Swedish Children's Cancer Foundation, the Swedish Research Council, Märta och Gunnar V Philipson's Foundation, the Cancer and Allergy Foundation of Sweden, Karolinska Institutet (KID project), and the Stockholm County Council (ALF project). The authors thank $\mathrm{H}$. Macaire for inspiring BCL2 figures of the paper.

\section{References}

[1] C. Cheong, I. Matos, J. H. Choi et al., "Microbial stimulation fully differentiates monocytes to DC-SIGN/CD209(+) dendritic cells for immune T cell areas," Cell, vol. 143, pp. 416-429, 2010.

[2] P. O. Vidalain, O. Azocar, B. Lamouille, A. Astier, C. RabourdinCombe, and C. Servet-Delprat, "Measles virus induces functional TRAIL production by human dendritic cells," Journal of Virology, vol. 74, no. 1, pp. 556-559, 2000.

[3] T. S. Griffith, S. R. Wiley, M. Z. Kubin, L. M. Sedger, C. R. Maliszewski, and N. A. Fanger, "Monocyte-mediated tumoricidal activity via the tumor necrosis factor- related cytokine, TRAIL," Journal of Experimental Medicine, vol. 189, no. 8, pp. 1343-1354, 1999.

[4] A. Rivollier, M. Mazzorana, J. Tebib et al., "Immature dendritic cell transdifferentiation into osteoclasts: a novel pathway sustained by the rheumatoid arthritis microenvironment," Blood, vol. 104, no. 13, pp. 4029-4037, 2004.

[5] Y. Fujikawa, J. M. W. Quinn, A. Sabokbar, J. O. D. McGee, and N. A. Athanasou, "The human osteoclast precursor circulates in the monocyte fraction," Endocrinology, vol. 137, no. 9, pp. 40584060, 1996.

[6] L. Bar-On and S. Jung, "Defining dendritic cells by conditional and constitutive cell ablation," Immunological Reviews, vol. 234, no. 1, pp. 76-89, 2010.

[7] F. Coury, N. Annels, A. Rivollier et al., "Langerhans cell histiocytosis reveals a new IL-17A-dependent pathway of dendritic cell fusion," Nature Medicine, vol. 14, no. 1, pp. 81-87, 2008.

[8] T. Korn, E. Bettelli, M. Oukka, and V. K. Kuchroo, "IL-17 and Th17 cells," Annual Review of Immunology, vol. 27, pp. 485-517, 2009.

[9] T. Braun and J. Zwerina, "Positive regulators of osteoclastogenesis and bone resorption in rheumatoid arthritis," Arthritis Research \& Therapy, vol. 13, article 235, 2011.

[10] C. E. T. da Costa, N. E. Annels, C. M. J. M. Faaij, R. G. Forsyth, P. C. W. Hogendoorn, and R. M. Egeler, "Presence of osteoclast-like multinucleated giant cells in the bone and nonostotic lesions of Langerhans cell histiocytosis," Journal of Experimental Medicine, vol. 201, no. 5, pp. 687-693, 2005.

[11] I. Murakami, A. Morimoto, T. Oka et al., "IL-17A receptor expression differs between subclasses of Langerhans cell histiocytosis, which might settle the IL-17A controversy," Virchows Archiv, vol. 462, no. 2, pp. 219-228, 2013.

[12] J. Yamashita, N. S. Datta, Y. H. P. Chun et al., "Role of Bcl2 in osteoclastogenesis and PTH anabolic actions in bone," Journal of Bone and Mineral Research, vol. 23, pp. 621-632, 2008.

[13] S. Olsson Åkefeldt, C. Maisse, A. Belot et al., "Chemoresistance of human monocyte-derived dendritic cells is regulated by IL17A," PLoS One, vol. 8, no. 2, Article ID e56865, 2013.

[14] V. S. Marsden and A. Strasser, "Control of apoptosis in the immune system: Bcl-2, BH3-only proteins and more," Annual Review of Immunology, vol. 21, pp. 71-105, 2003.

[15] F. Willems, Z. Amraoui, N. Vanderheyde et al., "Expression of c-FLIP(L) and resistance to CD95-mediated apoptosis of monocyte-derived dendritic cells: inhibition by bisindolylmaleimide," Blood, vol. 95, no. 11, pp. 3478-3482, 2000.

[16] C. Nicolò, B. Tomassini, M. R. Rippo, and R. Testi, "UVBinduced apoptosis of human dendritic cells: contribution by caspase-dependent and caspase-independent pathways," Blood, vol. 97, no. 6, pp. 1803-1808, 2001.

[17] R. J. Youle and A. Strasser, "The BCL-2 protein family: opposing activities that mediate cell death," Nature Reviews Molecular Cell Biology, vol. 9, no. 1, pp. 47-59, 2008.

[18] J. M. Adams and S. Cory, "The Bcl-2 apoptotic switch in cancer development and therapy," Oncogene, vol. 26, no. 9, pp. 13241337, 2007.

[19] V. S. Marsden, L. O’Connor, L. A. O’Reilly et al., “Apoptosis initiated by Bcl-2-regulated caspase activation independently of the cytochrome c/Apaf-1/caspase-9 apoptosome," Nature, vol. 419, no. 6907, pp. 634-637, 2002.

[20] A. G. Letai, "Diagnosing and exploiting cancer's addiction to blocks in apoptosis," Nature Reviews Cancer, vol. 8, no. 2, pp. 121-132, 2008. 
[21] G. L. Kelly and A. Strasser, "The essential role of evasion from cell death in cancer," Advances in Cancer Research, vol. 111, pp. 39-96, 2011.

[22] R. W. Craig, "MCL1 provides a window on the role of the BCL2 family in cell proliferation, differentiation and tumorigenesis," Leukemia, vol. 16, no. 4, pp. 444-454, 2002.

[23] P. Hampson, J. Hazeldine, and J. M. Lord, "Neutrophil apoptosis and its induction as a potential treatment for chronic inflammatory disease," Current Opinion in Hematology, vol. 20, pp. 10-15, 2013.

[24] W. L. W. Chang, N. Baumgarth, M. K. Eberhardt et al., "Exposure of myeloid dendritic cells to exogenous or endogenous IL-10 during maturation determines their longevity," Journal of Immunology, vol. 178, no. 12, pp. 7794-7804, 2007.

[25] A. la Sala, S. Corinti, M. Federici, H. U. Saragovi, and G. Girolomoni, "Ligand activation of nerve growth factor receptor TrKA protects monocytes from apoptosis," Journal of Leukocyte Biology, vol. 68, no. 1, pp. 104-110, 2000.

[26] E. Ottina, D. Tischner, M. J. Herold, and A. Villunger, "A1/Bfl1 in leukocyte development and cell death," Experimental Cell Research, vol. 318, pp. 1291-1303, 2012.

[27] D. Hanahan and R. A. Weinberg, "Hallmarks of cancer: the next generation,” Cell, vol. 144, no. 5, pp. 646-674, 2011.

[28] P. Miossec and J. K. Kolls, "Targeting IL-17 and TH17 cells in chronic inflammation," Nature Reviews Drug Discovery, vol. 11, pp. 763-776, 2012.

[29] W. Sieghart, D. Losert, S. Strommer et al., "Mcl-1 overexpression in hepatocellular carcinoma: a potential target for antisense therapy," Journal of Hepatology, vol. 44, no. 1, pp. 151-157, 2006.

[30] S. Thomas, B. A. Quinn, S. K. Das et al., "Targeting the Bcl2 family for cancer therapy," Expert Opinion on Therapeutic Targets, vol. 17, pp. 61-75, 2013.

[31] M. F. van Delft, A. H. Wei, K. D. Mason et al., "The BH3 mimetic ABT-737 targets selective Bcl-2 proteins and efficiently induces apoptosis via Bak/Bax if Mcl-1 is neutralized," Cancer Cell, vol. 10, no. 5, pp. 389-399, 2006.

[32] M. Vogler, M. Butterworth, A. Majid et al., "Concurrent upregulation of BCL-XL and BCL2A1 induces approximately 1000-fold resistance to ABT-737 in chronic lymphocytic leukemia," Blood, vol. 113, no. 18, pp. 4403-4413, 2009.

[33] D. Yecies, N. E. Carlson, J. Deng, and A. Letai, "Acquired resistance to ABT-737 in lymphoma cells that up-regulate MCL1 and BFL-1," Blood, vol. 115, no. 16, pp. 3304-3313, 2010.

[34] S. H. Kaufmann, J. E. Karp, P. A. Svingen et al., "Elevated expression of the apoptotic regulator Mcl-1 at the time of leukemic relapse," Blood, vol. 91, no. 3, pp. 991-1000, 1998.

[35] A. A. Morales, A. Olsson, F. Celsing, A. Österborg, M. Jondal, and L. M. Osorio, "High expression of bfl-1 contributes to the apoptosis resistant phenotype in B-cell chronic lymphocytic leukemia," International Journal of Cancer, vol. 113, no. 5, pp. 730-737, 2005.

[36] M. Nguyen, R. C. Marcellus, A. Roulston et al., "Small molecule obatoclax (GX15-070) antagonizes MCL-1 and overcomes MCL-1-mediated resistance to apoptosis," Proceedings of the National Academy of Sciences of the United States of America, vol. 104, no. 49, pp. 19512-19517, 2007.

[37] J. Wei, S. Kitada, M. F. Rega et al., "Apogossypol derivatives as antagonists of antiapoptotic Bcl-2 family proteins," Molecular Cancer Therapeutics, vol. 8, no. 4, pp. 904-913, 2009.
[38] M. Rahmani, E. M. Davis, T. R. Crabtree et al., "The kinase inhibitor sorafenib induces cell death through a process involving induction of endoplasmic reticulum stress," Molecular and Cellular Biology, vol. 27, no. 15, pp. 5499-5513, 2007.

[39] S. Kitada, J. M. Zapata, M. Andreeff, and J. C. Reed, "Protein kinase inhibitors flavopiridol and 7-hydroxy-staurosporine down- regulate antiapoptosis proteins in B-cell chronic lymphocytic leukemia," Blood, vol. 96, no. 2, pp. 393-397, 2000.

[40] A. Schnaiter and S. Stilgenbauer, "Refractory chronic lymphocytic leukemia-new therapeutic strategies," Oncotarget, vol. 1, no. 7, pp. 472-482, 2010.

[41] J. R. Jackson, D. R. Patrick, M. M. Dar, and P. S. Huang, "Targeted anti-mitotic therapies: can we improve on tubulin agents?” Nature Reviews Cancer, vol. 7, no. 2, pp. 107-117, 2007.

[42] I. E. Wertz, S. Kusam, C. Lam et al., "Sensitivity to antitubulin chemotherapeutics is regulated by MCL1 and FBW7," Nature, vol. 471, pp. 110-114, 2011.

[43] M. C. Genovese, F. Van den Bosch, S. A. Roberson et al., "LY2439821, a humanized anti-interleukin-17 monoclonal antibody, in the treatment of patients with rheumatoid arthritis: a phase I randomized, double-blind, placebo-controlled, proofof-concept study," Arthritis and Rheumatism, vol. 62, no. 4, pp. 929-939, 2010.

[44] A. R. Pettit, K. P. MacDonald, B. O'Sullivan, and R. Thomas, "Differentiated dendritic cells expressing nuclear RelB are predominantly located in rheumatoid synovial tissue perivascular mononuclear cell aggregates," Arthritis and Rheumatism, vol. 43, pp. 791-800, 2000.

[45] R. Thomas, K. P. A. MacDonald, A. R. Pettit, L. L. Cavanagh, J. Padmanabha, and S. Zehntner, "Dendritic cells and the pathogenesis of rheumatoid arthritis," Journal of Leukocyte Biology, vol. 66, no. 2, pp. 286-292, 1999.

[46] M. H. Wenink, W. Han, R. E. Toes, and T. R. Radstake, "Dendritic cells and their potential implication in pathology and treatment of rheumatoid arthritis," Handbook of Experimental Pharmacology, vol. 188, pp. 81-98, 2009.

[47] S. L. Jongbloed, M. C. Lebre, A. R. Fraser et al., "Enumeration and phenotypical analysis of distinct dendritic cell subsets in psoriatic arthritis and rheumatoid arthritis," Arthritis Research and Therapy, vol. 8, no. 1, article R15, 2006.

[48] N. J. Zvaifler, R. M. Steinman, G. Kaplan, L. L. Lau, and M. Rivelis, "Identification of immunostimulatory dendritic cells in the synovial effusions of patients with rheumatoid arthritis," The Journal of Clinical Investigation, vol. 76, no. 2, pp. 789-800, 1985.

[49] B. P. Leung, M. Conacher, D. Hunter, I. B. McInnes, F. Y. Liew, and J. M. Brewer, "A novel dendritic cell-induced model of erosive inflammatory arthritis: distinct roles for dendritic cells in T cell activation and induction of local inflammation," Journal of Immunology, vol. 169, no. 12, pp. 7071-7077, 2002.

[50] J. H. Esensten, D. Wofsy, and J. A. Bluestone, "Regulatory T cells as therapeutic targets in rheumatoid arthritis," Nature Reviews Rheumatology, vol. 5, no. 10, pp. 560-565, 2009.

[51] S. Khan, J. D. Greenberg, and N. Bhardwaj, "Dendritic cells as targets for therapy in rheumatoid arthritis," Nature Reviews Rheumatology, vol. 5, no. 10, pp. 566-571, 2009.

[52] H. Liu, P. Eksarko, V. Temkin et al., "Mcl-1 is essential for the survival of synovial fibroblasts in rheumatoid arthritis," Journal of Immunology, vol. 175, no. 12, pp. 8337-8345, 2005.

[53] J. C. Scatizzi, J. Hutcheson, R. M. Pope et al., "Bim-Bcl2 homology 3 mimetic therapy is effective at suppressing inflammatory arthritis through the activation of myeloid cell 
apoptosis," Arthritis and Rheumatism, vol. 62, no. 2, pp. 441-451, 2010.

[54] R. D. Oliveira, V. Fontana, C. M. Junta et al., "Differential gene expression profiles may differentiate responder and nonresponder patients with rheumatoid arthritis for methotrexate (MTX) monotherapy and MTX plus tumor necrosis factor inhibitor combined therapy," The Journal of Rheumatology, vol. 39, pp. 1524-1532, 2012.

[55] E. Segura, M. Touzot, A. Bohineust et al., "Human inflammatory dendritic cells induce Th17 cell differentiation," Immunity, vol. 38, no. 2, pp. 336-348, 2013.

[56] J. N. Stoop, J. H. Robinson, and C. M. U. Hilkens, "Developing tolerogenic dendritic cell therapy for rheumatoid arthritis: what can we learn from mouse models?" Annals of the Rheumatic Diseases, vol. 70, no. 9, pp. 1526-1533, 2011.

[57] G. Badalian-Very, J. A. Vergilio, M. Fleming, and B. J. Rollins, "Pathogenesis of langerhans cell histiocytosis," Annual Review of Pathology, vol. 8, pp. 1-20, 2013.

[58] R. Maarten Egeler, A. G. S. van Halteren, P. C. W. Hogendoorn, J. D. Laman, and P. J. M. Leenen, "Langerhans cell histiocytosis: fascinating dynamics of the dendritic cell-macrophage lineage," Immunological Reviews, vol. 234, no. 1, pp. 213-232, 2010.

[59] C. E. Allen, L. Li, T. L. Peters et al., "Cell-specific gene expression in Langerhans cell histiocytosis lesions reveals a distinct profile compared with epidermal Langerhans cells," Journal of Immunology, vol. 184, no. 8, pp. 4557-4567, 2010.

[60] C. Hutter, M. Kauer, I. Simonitsch-Klupp et al., "Notch is active in Langerhans cell histiocytosis and confers pathognomonic features on dendritic cells," Blood, vol. 120, pp. 5199-5208, 2012.

[61] B. Senechal, G. Elain, E. Jeziorski et al., "Expansion of regulatory T cells in patients with langerhans cell histiocytosis," PLoS Medicine, vol. 4, no. 8, article e253, 2007.

[62] M. Aricò, K. Nichols, J. A. Whitlock et al., "Familial clustering of Langerhans cell histiocytosis," British Journal of Haematology, vol. 107, no. 4, pp. 883-888, 1999.

[63] G. Badalian-Very, J. A. Vergilio, B. A. Degar et al., "Recurrent BRAF mutations in Langerhans cell histiocytosis," Blood, vol. 116, pp. 1919-1923, 2010.

[64] F. Sahm, D. Capper, M. Preusser et al., "BRAFV600E mutant protein is expressed in cells of variable maturation in Langerhans cell histiocytosis," Blood, vol. 120, pp. 28-34, 2012.

[65] T. Satoh, A. Smith, A. Sarde et al., "B-RAF mutant alleles associated with Langerhans cell histiocytosis, a granulomatous pediatric disease," PLoS One, vol. 7, Article ID e33891, 2012.

[66] K. E. Nichols and R. J. Arceci, "BRAF, a piece of the LCH puzzle," Blood, vol. 116, no. 11, pp. 1825-1827, 2010.

[67] M. I. Bank, C. Gudbrand, P. Rengtved et al., "Immunohistochemical detection of the apoptosis-related proteins FADD, FLICE, and FLIP in Langerhans cell histiocytosis," Journal of Pediatric Hematology/Oncology, vol. 27, no. 6, pp. 301-306, 2005.

[68] V. H. Savell Jr., T. Sherman, R. H. Scheuermann, A. M. Siddiqui, and L. R. Margraf, "Bcl-2 expression in Langerhans' cell histiocytosis," Pediatric and Developmental Pathology, vol. 1, no. 3, pp. 210-215, 1998.

[69] B. Schouten, R. M. Egeler, P. J. M. Leenen, A. H. M. Taminiau, L. J. C. M. van den Broek, and P. C. W. Hogendoorn, "Expression of cell cycle-related gene products in Langerhans cell histiocytosis," Journal of Pediatric Hematology/Oncology, vol. 24, no. 9, pp. 727-732, 2002.

[70] J. Marchal, M. Kambouchner, A. Tazi, D. Valeyre, and P. Soler, "Expression of apoptosis-regulatory proteins in lesions of pulmonary Langerhans cell histiocytosis," Histopathology, vol. 45, no. 1, pp. 20-28, 2004.

[71] C. Michaloglou, L. C. W. Vredeveld, W. J. Mooi, and D. S. Peeper, "BRAFE600 in benign and malignant human tumours," Oncogene, vol. 27, no. 7, pp. 877-895, 2008.

[72] J. H. de Graaf, R. Y. Tamminga, A. Dam-Meiring, W. A. Kamps, and W. Timens, "The presence of cytokines in Langerhans' cell histiocytosis," The Journal of Pathology, vol. 180, pp. 400-406, 1996.

[73] R. M. Egeler, B. E. Favara, M. van Meurs, J. D. Laman, and E. Claassen, "Differential in situ cytokine profiles of Langerhanslike cells and T cells in Langerhans cell histiocytosis: abundant expression of cytokines relevant to disease and treatment," Blood, vol. 94, no. 12, pp. 4195-4201, 1999.

[74] M. Comabella, X. Montalban, C. Münz, and J. D. Lünemann, "Targeting dendritic cells to treat multiple sclerosis," Nature Reviews Neurology, vol. 6, no. 9, pp. 499-507, 2010.

[75] K. Palucka, J. Banchereau, and I. Mellman, "Designing vaccines based on biology of human dendritic cell subsets," Immunity, vol. 33, no. 4, pp. 464-478, 2010.

[76] I. Caminschi, E. Maraskovsky, and W. R. Heath, "Targeting dendritic cells in vivo for cancer therapy," Frontiers in Immunology, vol. 3, article 13, 2012. 


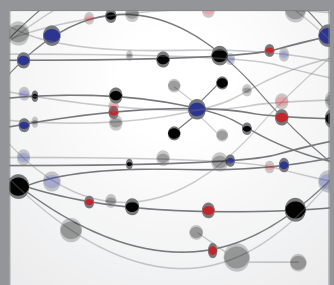

The Scientific World Journal
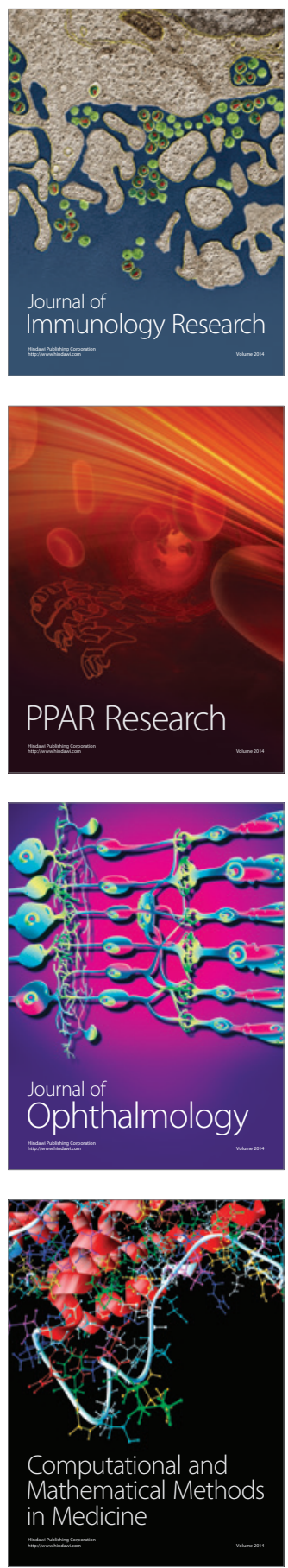

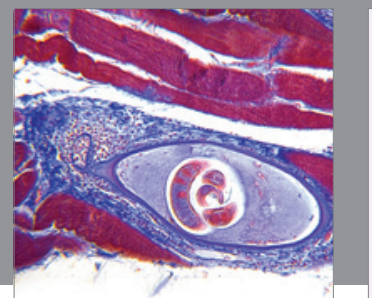

Gastroenterology

Research and Practice
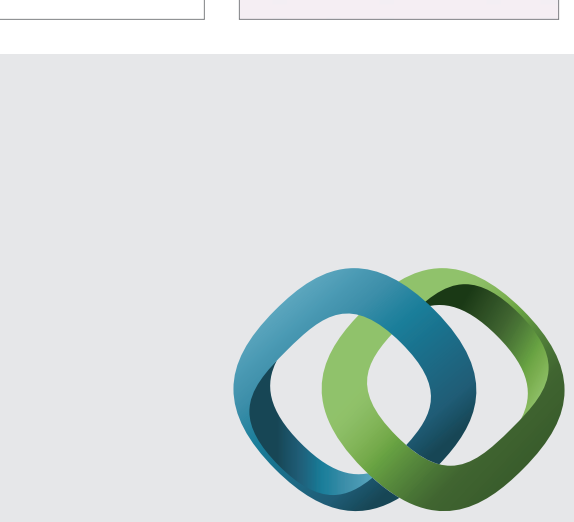

\section{Hindawi}

Submit your manuscripts at

http://www.hindawi.com
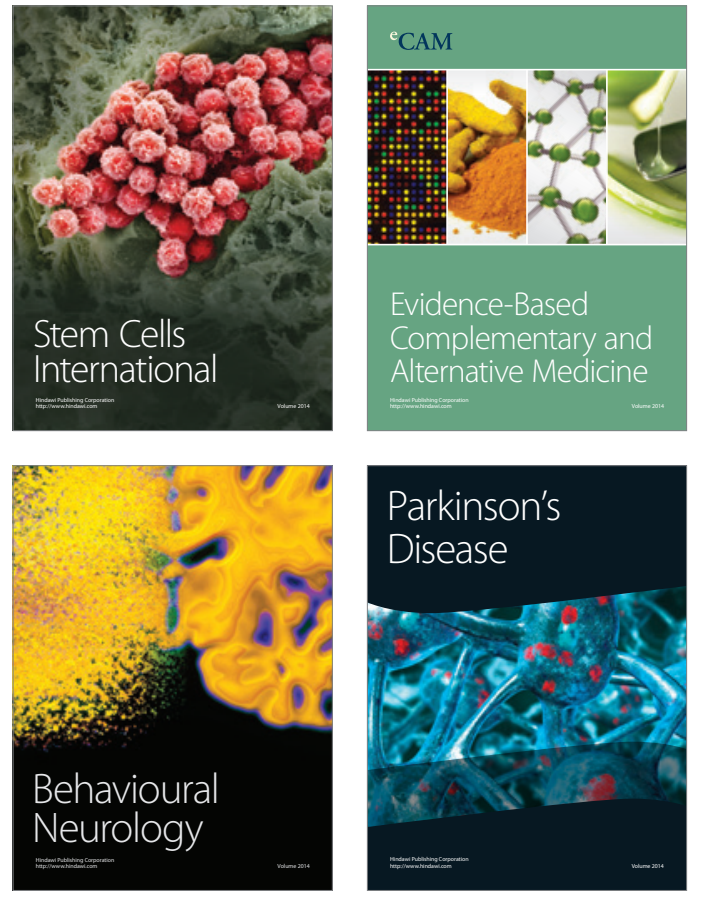
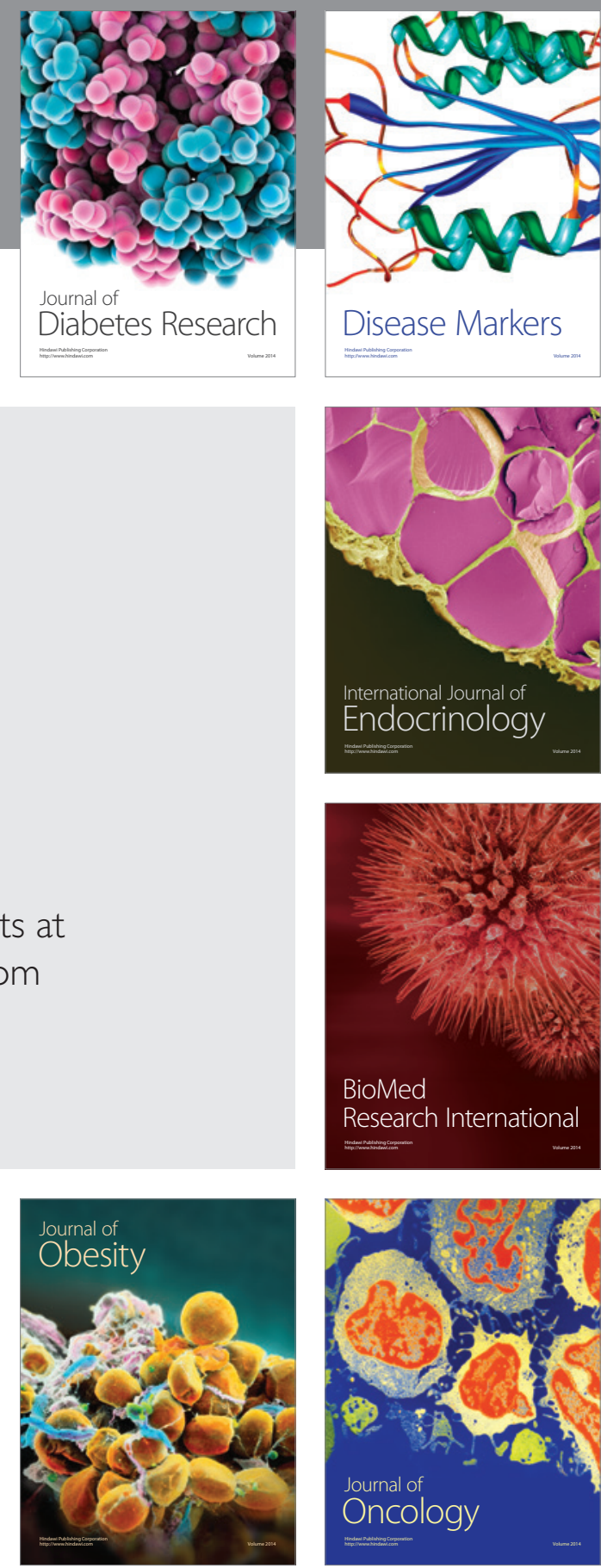

Disease Markers
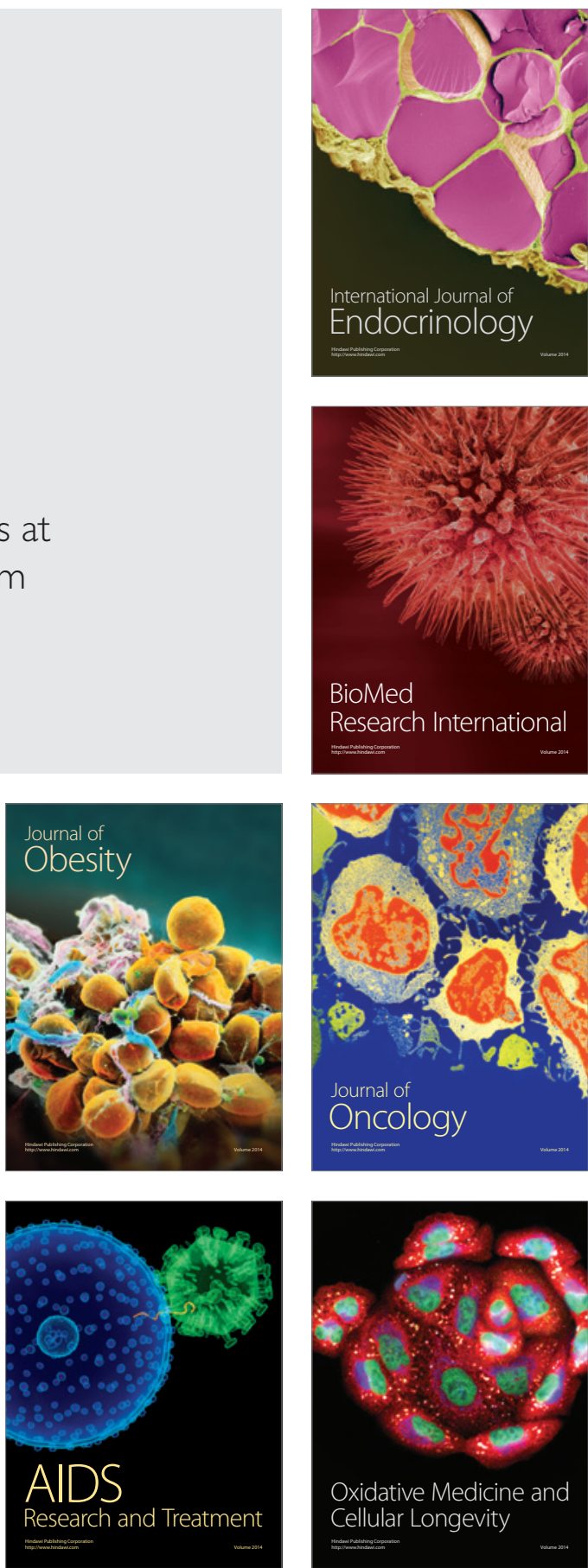